\title{
Jan Van Dijk: \\ The Network Society. \\ London: Sage Publications. 2012.
}

\section{Sandy Schumann}

MedieKultur 2013, 54, 189-192

Published by SMID | Society of Media researchers In Denmark | www.smid.dk The online version of this text can be found open access at www.mediekultur.dk

As the Internet became increasingly popular in the early 1990 s, its potential impact on individuals, organizations, and society was repeatedly discussed in public debates and investigated across scientific disciplines. For instance, besides changing practices of interpersonal communication and challenging the understanding of privacy, the advance of information technology was also argued to affect notions of space and time. Jan van Dijk's third edition of The Network Society (2012) provides a comprehensive and interdisciplinary overview of this discourse and summarizes established frameworks and findings concerning the social impact of new media. The author considers contributions from cultural, legal, and organizational studies; psychology; and economics. But rather than highlighting selected phenomena in detail, the book briefly reviews multiple trends in different sectors of society.

Throughout The Network Society, Van Dijk refers to several examples of new media, including social media, computer-mediated communication (CMC), e-books, knowledge sharing platforms, and e-voting systems. This may surprise readers who expect from the book's title a focus on media, social, or technical networks. However, the interrelatedness of the concepts becomes evident when considering the theoretical underpinning of the book, which follows network, structuration, and medium theory. The author defines new media as a result of merging media and social networks and as an indicator of a second structural communication ( $r$ )evolution in which media networks become the new lifeline of society, a network society. In other words, social networks of individuals, groups, and organizations that are realized on the Internet and mobile telephone networks constitute 
the development of new media. The network nodes are as important as are its connections, and while new media affects its users, these users also shape the nature of new media. Van Dijk cautions us not to conclude that new media will drastically change societal practices and processes. The central message of the book is that new media is amplifying rather than altering existing trends. This implies that new media is neither neutral nor beneficial or harmful per se. Its impact always reflects the current social, cultural, and political context, despite standardized structural and technical characteristics.

As part of an introduction to fundamental concepts, Van Dijk dedicates Chapters 1 and 3 to the latter and concludes with how attributes of new media can change information patterns in social networks. For example, the capability of storing data enables asynchronous communication and the administration of resources. This, along with the interactive nature of new media, gives individuals, groups, and organizations the power to research and exchange information independently, without relying on central network units.

In Chapter 2, the author extends this argument and proposes seven network 'laws', which highlight how network qualities define the effect of new media on society. Van Dijk argues, for instance, that as more people enter a network, others wish to join as well. To ensure access to information in growing networks, intermediaries - such as social network sites - become necessary. At the same time, individuals' attention will become more selective, and the fight for audiences will be won by those that are already popular, making the rich richer.

With these postulations in mind, the author discusses in the following five chapters the impact of new media on specific societal domains. Chapter 4 focuses on the global flow economy, where production, distribution, and consumption are connected within and between companies. New media supports companies' need for flexibility and efficiency, and the interactive nature of new media can even reverse the value chain, giving customers the power to alert companies to their demands. New media also literally affects the economy by creating new industries, the 'big players' of which strive to design media networks according to their business opportunities.

This aspect is further explored in Chapter 5 , which addresses how new media can shift power relations. The author thinks that it is an "unrealistic belief" (p. 111) that new media should intrinsically facilitate democracy and empower citizens or flatten bureaucratic structures. On the contrary, social network sites and e-mail are just as likely to be used to control citizens, enhancing the formalization and standardization of actions. To sum up, depending on the central actors, new media can both amplify and challenge power inequalities in society.

Chapter 6 also considers the concept of power but from a legal perspective. The key challenge for integrated networks is that information and communication are intangible, geographically independent, and constantly changing. New media makes global legal infringements easier, but country-specific jurisdictions complicate their prosecution. Furthermore, current legal rulings on the right for privacy do not, for example, take into 
account technological developments such as data mining tools. Ultimately, "governments and the media law [have] [...] no effective grip on Internet content" (p. 141) and leave Internet governance to corporations and software control.

In Chapter 7, Van Dijk focuses on how new media changes different aspects of the social structure. He rejects, for example, the idea that constraints of space and time are removed by new media. As they become multifunctional, it is even more important to coordinate what to do at which time in order to ensure orientation and routine. Reviewing the topic of social inequalities from Chapter 5 , the author also proposes that new media creates a hierarchy of jobs based on media skills. This means that the digital divide is not just a matter of access to the Internet but also of having the ability to use new media professionally or to create digital culture.

Chapter 8 introduces the latter concept, defined as a shared set of expressions, artifacts, and products that are developed using pre-programmed means of new media. Van Dijk states that, despite the many options for content creation, the majority of users will prefer consumption over the production of digital culture. Speculating on further trends in new media use, the author predicts that media will not converge into a single medium, the Internet, and that new will not replace old media. Diversity and contextualization - rather than multi-functionality - will define media in the future.

To round up the previous chapters, Van Dijk points out in Chapter 9 how new media may change human experience of everyday life. Computer-mediated communication can, for instance, influence interpersonal relationships. They become technology dependent but can also be more easily controlled. On a group level, coordination problems arise in CMC due to large input and lack of feedback, so that norms as well as leadership need to develop over time. In conclusion, Van Dijk argues that, rather than highlighting differences between face-to-face and CMC, research should examine how online and offline communication are being integrated.

The last chapter of The Network Society summarizes the key conclusions in terms of policy implications. Van Dijk highlights that universal access to computers and development of digital skills should be a priority for governments. Due to their central role in society, precautions against network vulnerabilities must be taken and attacks on media networks foreseen. The author further argues that Internet governance to determine the Internet's design and control should be shared, combining legal and technological solutions as well as self-regulation of the Internet community.

As is visible from this summary, the broad approach of The Network Society is certainly one of the book's appealing qualities. By urging the reader to understand how new media affects society from a holistic perspective, Van Dijk conceptualizes new media as a technological, social, economic, political, cultural, and legal phenomenon. The author remains reflective throughout the book and refrains from Internet optimism that sees new media as the solution to all societal problems. I believe that The Network Society is thus a substantial contribution to the field of Internet research.It must, however, be mentioned that 
the richness of information hinders at certain points the book's readability. Its structure, aligned with fields of society that new media affects, promises to act as a great guide for the reader. But some topics seem to be forced into chapters. For example, in Chapter 7 , the influences of new media on the blurring of spheres of living are explored. While the references to distance education and a classification of social media as a medium that blurs interpersonal and mass communication feel very natural, the subsequent explanation for the delayed arrival of social media is surprising and leaves the reader waiting for the previous argument to be picked up again.

Overall, however, The Network Society is an excellent introductory textbook for students and scholars of digital humanities, new media, information sciences, and communication sciences. Likewise, practitioners such as IP lawyers and civic organizations that wish to use new media to achieve social change can benefit from the book. In addition, all arguments are based on sound theoretical models, but the language and didactic style of The Network Society are also appropriate for those outside of academia. All chapters start with a summary of what to expect in the section and conclude with 'take-home messages', making it easy to use The Network Society as a reference throughout one's research and study.

Sandy Schumann

PhD student \& FNRS Research Fellow

Research Center for Social and Cultural Psychology

Université Libre de Bruxelles, Belgium

sandy.schumann@ulb.ac.be 